\title{
Fazer investigação self-study na formação inicial de professores: A importância de ouvir os alunos futuros professores
}

\author{
Tom Russell ${ }^{1}$ (D) @ \\ Maria Assunção Flores ${ }^{2}$ \\ ${ }^{1}$ Universidade de Queen, Canadá; ${ }^{2}$ Universidade do Minho, Portugal
}

Resumo. Os dois self-studies da prática de formação de professores que se descrevem neste artigo foram conduzidos de forma colaborativa em dois países diferentes - Portugal e Canadá. O enfoque principal deste artigo reside na importância de ouvir os alunos futuros professores e no modo como os autores interpretaram e responderam ao que ouviram. De um modo geral, ouvir e responder proporcionou respostas positivas por parte dos alunos futuros professores. Este artigo ilustra as várias maneiras de ouvir os alunos e os seus efeitos positivos quer nos alunos futuros professores, quer nos formadores. A pedagogia da formação de professores constitui uma preocupação central para os que se encontram a aprender a ensinar: o modo como são ensinados conta, pois eles estão sempre a pensar sobre o modo como eles próprios irão ensinar. Os autores defendem a importância de tornar transparente a pedagogia dos formadores de professores, o que passa pela explicitação da nossa racionalidade e da explicação do como e do porquê inerentes às mudanças decorrentes dos comentários dos alunos futuros professores. Este artigo inclui o contexto da investigação no âmbito do self-study da prática dos formadores de professores, ilustra o self-study com dados recolhidos junto dos alunos nas aulas dos autores e sintetiza o que os autores aprenderam em termos de mudança de pressupostos e de novas práticas pedagógicas.

Palavras-chave: self-studies; formadores de professores; pedagogia da formação de professores; alunos futuros professores; prática dos formadores de professores.

\begin{abstract}
Hacer investigación self-study en la formación inicial del profesorado: La importancia de oír a los futuros profesores

Resumen. Los dos self-studies de la práctica de formación de profesores descritos en este artículo se desarrollaron de forma colaborativa en dos países: Portugal y Canadá. Se centra en la importancia de escuchar a los estudiantes como futuros profesores y en como los autores del artículo han interpretado y contestado lo que escucharon. En general, oír y contestar han proporcionado respuestas positivas por parte de los futuros docentes. El artículo muestra distintas maneras de escuchar a los estudiantes y sus efectos positivos, tanto como futuros profesores como formadores. La formación pedagógica del profesorado constituye una preocupación primordial de quienes están aprendiendo a enseñar: el modo como se les enseña es importante, porque revertirá en el modo de como ellos van a enseñar. Los autores defienden lo relevante que es evidenciar la práctica docente de los formadores de profesores, esto implica explicar nuestra racionalidad y explicar cómo y por qué es inherente a los cambios que surgen de los comentarios de futuros estudiantes docentes. La investigación se desarrolla en el ámbito del self-study en la práctica docente de los formadores de profesores, muestra datos recopilados junto a los alumnos en las clases, y sintetiza lo que los autores han aprendido en términos de cambio de hipótesis y de nuevas prácticas pedagógicas.

Palabras clave: self-study; formadores de profesores; formación pedagógica de docentes; futuros profesores; práctica de los formadores del profesorado.
\end{abstract}

Doing self-study research on initial teacher training: The importance of hearing future teachers Abstract. The two self-studies of teacher education practices reported in this article were conducted collaboratively in two different countries - Portugal and Canada. The focus is on the value of listening to student teachers and how the authors interpreted and responded to what they heard. Overall, listening and responding yielded positive responses from the student teachers. This article illustrates several ways of listening to students and the positive effects of listening on both the student teachers and the teacher educators. The pedagogy of teacher education is a major concern for those learning to teach: How they are taught matters, for they are always thinking about how they themselves will teach. The authors believe strongly in the importance of making a teacher educators' pedagogy transparent by explaining our rationales and by explaining how and why we are making changes in response to their comments. This article provides background about the research genre of self-study of teacher education practices, illustrates self-study with data from the student teachers in the authors' classes, and summarizes what the authors learned in terms of changing assumptions and new pedagogical practices.

Keywords: self-studies; teacher educators; pedagogy of teacher education; student teachers; teacher educators' practice. 


\section{Introdução}

0 trabalho, identidade e oportunidades de desenvolvimento profissional dos formadores de professores têm atraído vários investigadores nos últimos anos. Contudo, as questões sobre quem são, o que fazem e como entendem os seus papéis parecem ter diversas respostas na literatura neste domínio (ver, por exemplo, Izadinia 2014; Livingston 2014; Czerniawski, Guberman \& MacPhail 2017; Meeus, Cools \& Placklé 2018; Bouckaert \& Kools 2018; White 2019). De um modo geral, os formadores dos professores são descritos como professores de professores envolvidos na aprendizagem profissional dos futuros professores (Murray, Swennen \& Shagrir 2009). Numa revisão recente de artigos empíricos, Ping, Schellings e Beijaard (2018, p. 93) concluíram que "a investigação sobre a aprendizagem profissional dos formadores de professores surge como um campo de interesse crescente mas ainda fragmentário em termos de enfoque". Os mesmos autores também assinalaram que i) não existe um conhecimento base claro essencial para o trabalho dos formadores de professores; ii) os formadores de professores desempenham diferentes atividades a partir das quais aprendem; e iii) os formadores de professores geralmente necessitam de aprender a fazer o seu trabalho como formadores de professores. Além disso, os formadores de professores têm sido descritos como um grupo peculiar de professores porque as suas práticas pedagógicas são significativamente diferentes das de outros professores do ensino superior no que diz respeito ao uso de vários tipos de estratégias tradicionais e construtivistas (Goubeaud \& Yan 2004).

Apesar da falta de consistência existente na literatura sobre as suas identidades e suas as oportunidades de aprendizagem e desenvolvimento profissional, os formadores de professores são vistos como "atores cruciais para manter - e melhorar - a elevada qualidade dos professores" (Comissão Europeia, 2013, p. 4). Assim, os formadores de professores são descritos como agentes transformadores de "reformas locais" que respondem às exigências educacionais e sociais (Moreira \& Vieira 2012). Deste modo, é necessário investigar mais sobre o modo como os formadores de professores aprendem, como ensinam a aprender e como veem a sua prática e as estratégias para a melhorar. Neste contexto, os self-studies da formação de professores podem e devem assumir um papel determinante na compreensão e no questionamento dos programas, processos e práticas de formação (Loughran 2005, 2009; Kitchen 2005; Schulte 2005).

Enquanto campo de investigação reconhecido, o self-study das práticas de formação começou em 1993 enquanto organização constituída por cerca de 300 formadores de professores. Em 1996, iniciou-se um conjunto de congressos internacionais bienais do self-study das práticas de formação de professores no Herstmonceux Castle, Reino Unido. Em 2004, 
foram publicados dois volumes do International Handbook sobre self-study (Loughran et al., 2004) e, em 2005, foi iniciada a publicação pela Routledge da revista científica Studying Teacher Education: A Journal of Self-Study of Teacher Education Practices. 0 campo do self-study das práticas de formação é agora reconhecido internacionalmente. Em 2017, foi ainda publicado um livro, no Chile, para disseminar o self-study no mundo falante de espanhol (Russell, Fuentealba \& Hirmas, 2017). Este trabalho está disponível e de acesso livre como ficheiro pdf.

Ping et al. (2018), numa revisão da literatura sobre a aprendizagem profissional dos formadores de professores, destacam o seguinte:

Fazer um self-study parece ser um tipo importante de investigação prática para os formadores de professores que Ihes permite refletir e analisar as suas próprias práticas ou pressupostos sobre aprender e ensinar com vista à melhoria das suas práticas de ensino. (p.100)

O self-study proporciona uma abordagem eficaz para os formadores de professores explorarem o porquê das suas rotinas nas suas práticas de ensino quotidianas, colocando a indagação no centro da aprendizagem e do ensino sobre o ensino. Os argumentos relacionados com a "qualidade" [do] self-study enquanto investigação prendem-se com a tensão entre a relevância científica e o rigor da investigação, por um lado, e, por outro, a compreensão da investigação e a sua eficácia prática. (p. 102)

Para entender as práticas de investigação dos formadores de professores que conduzem investigação sobre o seu próprio ensino, é importante introduzir o conceito de aprendizagem single-loope double-loop. A aprendizagem single-loop envolve a aprendizagem para realizar ações corretivas quando uma situação da prática se afasta das condições desejáveis. Por seu turno, a aprendizagem double-loop requer que a aprendizagem questione por que é que as condições desejáveis são consideradas desejáveis e também se outras condições poderiam melhorar a prática. Estes dois tipos de aprendizagem são descritos claramente por Argyris (1991), que escreveu o seguinte sobre a aprendizagem double-loop:

Dito de forma simples, devido ao facto de muitos profissionais serem quase sempre bem-sucedidos no que fazem, raramente experienciam o falhanço. E porque raramente falham, nunca aprenderam sobre como aprender a partir do insucesso. Portanto, sempre que as suas estratégias de aprendizagem single-loop não funcionam, tornam-se defensivos, excluem as críticas e colocam a "culpa" em alguém ou em todos exceto neles próprios. Em suma, a sua capacidade para aprender termina precisamente no momento em que mais necessitam (p. 100).

A aprendizagem double-loop eficaz não é simplesmente uma função inerente ao modo como as pessoas sentem. Trata-se de uma reflexão sobre como pensam, isto é, as regras cognitivas ou o raciocínio que usam para planificar e implementar as suas ações. Pensem nessas regras como um tipo de "master program" armazenado no cérebro, conduzindo todo o comportamento (p. 100) 
Se não se conhecerem os conceitos de aprendizagem singlee doubleloop, é necessário tempo para se familiarizar com eles. Recomendamos estes conceitos no quadro de uma perspetiva importante dentro da metodologia de investigação self-study das práticas de formação de professores que LaBoskey (2004, pp.817-869) descreve a partir de cinco características essenciais: iniciada pelo próprio e com determinado enfoque; com vista à melhoria; interativa; com recurso a métodos múltiplos e sobretudo qualitativos e com uma validação baseada em exemplos (validação baseada em exemplos da prática normal).

Recomenda-se, normalmente, que o self-study das nossas práticas de formação possa ser conduzido com um amigo crítico - tipicamente um colega de confiança que possa ser crítico no sentido de colocar questões adicionais e perspetivas, enriquecendo a análise dos dados e apoiando a aprendizagem double-loop ao ajudar a explicitar os nossos pressupostos implícitos. Esta crítica tem como objetivo ser positiva, construtiva e encorajadora, mantendo a consistência com o enfoque que o formador pretende para o self-study. $\mathrm{Na}$ recolha de dados para os self-studies que se descrevem neste artigo, agimos como amigos críticos um do outro, com base no interesse comum de melhorar a formação de professores que desenvolvemos durante várias colaborações ao longo dos últimos seis anos. Costa e Kallick (1993) desenvolvem o conceito 14 de amigo crítico de forma mais detalhada.

Assim, realizar um self-study bem-sucedido das práticas de formação requer estratégias de aprendizagem double-loop que questionam não só "qual é a minha prática?" mas também "que pressupostos sobre ensino e aprendizagem estão subjacentes às minhas práticas e existirão outras práticas que podem melhorar a aprendizagem dos alunos futuros professores?". Neste artigo centramo-nos em dados dos self-studies das nossas práticas de formação realizadas em 2018-2019. 0 nosso objetivo é investigar as nossas práticas enquanto formadores de professores através do olhar dos nossos alunos de forma a compreender e melhorar a formação a partir de dentro.

\section{Estudar as práticas dos formadores de professores}

O self-study das práticas de formação de professores não constitui um fim em si mesmo, pois implica a consideração do fim mais amplo de melhorar a formação docente e a educação (Russell \& Loughran 2005). O self-study torna-se num elemento chave no desenvolvimento da pedagogia da formação de professores (Loughran 2005), ajudando a ultrapassar a visão errónea do ensino como mero "fazer" para incluir o "porquê" do ensino, contribuindo para o desenvolvimento de práticas mais informadas e significativas com vista 
à melhoria da aprendizagem dos alunos (Loughran \& Menter, 2019). Como os mesmos autores argumentam, "os formadores de professores devem eles próprios ser investigadores que facilitam a aprendizagem dos alunos futuros professores sobre 0 conhecimento $e$ sobre a prática de ensino através de programas de formação de qualidade" (Loughran \& Menter, 2019, p. 217, itálico no original). Os self-studies relatados neste artigo foram conduzidos de forma colaborativa nos dois países - Portugal e Canadá. 0 nosso enfoque reside no valor de ouvir os alunos e no modo como interpretamos e respondemos ao que ouvimos. De um modo geral, ouvir e responder proporcionou respostas positivas por parte dos alunos futuros professores. 0 nosso objetivo neste artigo é ilustrar as várias maneiras de ouvir os alunos e os seus efeitos positivos quer nos alunos futuros professores, quer nos formadores.

\section{Os self-studies}

\subsection{Contexto}

O self-study do Canadá foi realizado no contexto do Bacharelato em Educação certificado pelo Ontario College of Teachers. Tal como se descreve na Tabela 1, a disciplina em questão prepara os alunos a ensinar Física e Ciências no ensino secundário. Situado no trimestre 2 e 3 num programa de 4 trimestres, a disciplina tem a duração de 72 horas (2 horas por semana durante 18 semanas intercalada com dois estágios de 6 e 4 semanas). Os 14 alunos que frequentavam a disciplina foram avaliados com base em três trabalhos escritos por trimestre. Os métodos de ensino incluíram apresentações feitas pelos alunos para praticar, discussão de itens de teste focando na Física conceptual, rotinas de predizer-observar- explicar, revisão de investigação educacional em Física, discussões metacognitivas no final das aulas e realização de um breve exit-ticket no final de cada aula. Foram ainda utilizadas mensagens de email para partilhar materiais de leitura adicionais.

O self-study em Portugal foi conduzido no contexto do Mestrado em Ensino ${ }^{1}$ que constitui o grau exigido para todos os novos professores (desde a educação pré-escolar até ao ensino secundário). As principais características da disciplina onde decorreu o self-study - Currículo e Avaliação - são apresentadas na Tabela 1. Trata-se de uma disciplina obrigatória do $1^{\circ}$ semestre do $1^{\circ}$ ano para todos os Mestrados em Ensino com a duração de 45 horas (3 horas por semana). No total, participaram no estudo 20 alunos futuros

${ }^{1}$ Em resultado da implementação do processo de Bolonha, os cursos anteriores de 4 e 5 anos de formação ao nível da graduação foram substituídos por um modelo consecutivo: um curso de 3 anos numa determinada disciplina seguido de um mestrado de ensino de 2 anos. 
professores de História, Matemática e Informática. A disciplina procura desenvolver conhecimento e competências no design curricular e na avaliação da aprendizagem - dois elementos centrais na construção do conhecimento profissional docente. Os métodos de avaliação usados para avaliar o trabalho dos alunos foram escolhidos por eles e incluíram a escrita de um portefólio individual ao longo do semestre e um teste no final do semestre. Foi utilizada uma variedade de métodos de ensino, incluindo a redação de narrativas escritas (por exemplo, sobre o professor que mais me marcou); debates (por exemplo, os professores têm autonomia curricular, porquê? Por que não?; avaliação formativa versus avaliação sumativa; exames nacionais versus outros métodos de avaliação), vozes de alunos sobre os seus professores; discussões em grupo e trabalho prático. Foram também usadas mensagens de email frequentes para proporcionar aos alunos feedback sobre o portefólio. Os alunos futuros professores também leram e deram feedback aos seus pares sobre algumas entradas dos portefólios (por exemplo, sobre os incidentes críticos relacionados com a avaliação ou com o professor que mais os marcou).

Tabela 1. Dados sobre os contextos de investigação

\begin{tabular}{|c|c|c|}
\hline & Canadá & Portugal \\
\hline Curso & $\begin{array}{l}\text { Bachalerato de Educação } \\
\text { (programa de } 2 \text { anos depois do } \\
\text { Bacharelato em Ciências de } 4 \\
\text { anos) }\end{array}$ & $\begin{array}{l}\text { Mestrado em Ensino de } 2 \text { anos de- } \\
\text { pois de uma Licenciatura de } 3 \text { anos }\end{array}$ \\
\hline $\begin{array}{l}\text { Designação da } \\
\text { disciplina }\end{array}$ & $\begin{array}{l}\text { Teoria e prática de ensino de } \\
\text { Física }\end{array}$ & Currículo e Avaliação \\
\hline $\begin{array}{l}\text { Natureza da disci- } \\
\text { plina }\end{array}$ & $\begin{array}{l}\text { Obrigatória para os futuros } \\
\text { professores de Física }\end{array}$ & $\begin{array}{l}\text { Disciplina transversal e obrigatória } \\
\text { para todos os alunos futuros } \\
\text { professores }\end{array}$ \\
\hline Duração & 2 semestres (72 horas) & 1 semestre ( 45 horas) \\
\hline Objetivos principais & $\begin{array}{l}\text { Preparar os alunos para ensinar } \\
\text { ciência/física através de ativida- } \\
\text { des desenvolvidas nas aulas e } \\
\text { discussão; modelação de boas } \\
\text { práticas }\end{array}$ & $\begin{array}{l}\text { Desenvolver conhecimento e compe- } \\
\text { tências relacionadas com o design } \\
\text { curricular e com a avaliação da } \\
\text { aprendizagem dos alunos }\end{array}$ \\
\hline Número de alunos & 14 & 20 \\
\hline
\end{tabular}

\subsection{Os nossos pressupostos como formadores de professores}

Ambos os autores possuem mais de 25 anos de experiência como formadores de professores. 0 nosso esforço foi identificar e compreender as razões pelas quais ensinamos como ensinamos. Algumas das nossas crenças e práticas servem para indicar os pressupostos fundamentais do nosso trabalho como formadores de professores:

- A prática reflexiva pode e deve ser ensinada (Russell 2005).

Fomentar a prática reflexiva começa com uma relação pessoal entre ensino-aprendizagem baseada na confiança mútua, ... requer ouvir cada 
indivíduo como único,... deve incluir atenção ao que cada pessoa... aprendeu a partir da aprendizagem pela observação [como aluno], ... envolve promover a metacognição, ... exige a modelação explícita da nossa própria prática, ... centra-se na aprendizagem pela experiência, [e]... deve permear todos os passos pedagógicos que se façam (Russell 2014, pp. 58-60).

- Aprender a ensinar constitui um processo pessoal e reflexivo; é fundamental desenvolver pedagogias que promovam o processo de apreender a ser professor dando voz e espaço os alunos futuros professores para desafiarem e mudarem as suas crenças e experiências.

0 enfoque no aluno em vez de no currículo, a interação entre os alunos futuros professores, o trabalho baseado na indagação, a modelação da prática dos formadores de professores... a voz pedagógica, e a aprendizagem produtiva... são princípios-chave no desenho das disciplinas (Flores 2014, p. 375).

- A formação inicial de professores constitui um contexto fundamental para a formação da identidade profissional e as atividades baseadas na indagação e na reflexão são elementos centrais no processo de aprender a ensinar (Flores 2014)

- A modelação da aprendizagem produtiva e o dar sentido à reflexão através da própria prática dos formadores pode contribuir para desenvolver a identidade profissional e potenciar a aprendizagem profissional de forma mais explícita (Russell \& Martin 2014).

- Uma das dimensões centrais da formação inicial de professores consiste em proporcionar aos alunos futuros professores oportunidades para refletirem sobre os aspetos visíveis e invisíveis da experiência pedagógica (Loughran 2009).

Aprender a ensinar envolve uma constelação de fatores complexos. Trata-se de um processo que vai para além da mera aplicação de um conjunto de técnicas e destrezas adquiridas, implicando não só o domínio de aspetos práticos e mais técnicos mas também a construção de conhecimento e de sentido num diálogo contínuo e questionador com a prática (Flores 2001, p. 146).

\subsection{Métodos}

\subsubsection{Questões de investigação}

Decidimos recolher dados relevantes para as seguintes questões de investigação:

- Como é que os alunos futuros professores veem as nossas disciplinas no contexto do programa/curso que frequentam? 
- Como é que as nossas disciplinas ajudam os alunos a desenvolverem as suas visões de ensino e de aprendizagem?

- De que modo é que os tickets-out-of-class ajudam os professores e os alunos futuros professores a melhorarem a aprendizagem dos alunos?

\subsubsection{Participantes}

Todos os participantes tinham completado um curso de graduação e estavam inscritos num curso de formação inicial de 2 anos. A dimensão das turmas era de 14 e de 20 alunos, portanto relativamente pequenas, mas acreditamos que as nossas práticas podem ser adaptadas a turmas maiores.

\subsubsection{Métodos e procedimentos}

A investigação relatada neste artigo foi realizada com recurso a métodos habituais no self-study das práticas de formação de professores. LaBoskey (2004) identificou cinco características essenciais, destacando que a investigação self-study é iniciada pelo próprio e com determinado enfoque; tem como objetivo a melhoria; é interativa; recorre a métodos múltiplos e sobretudo qualitativos e implica uma validação baseada em exemplos da prática diária. Esta investigação centra-se na melhoria das nossas práticas como formadores de professores apoiada pela interação entre os dois investigadores, usando métodos qualitativos para recolher e analisar os dados recolhidos junto dos nossos alunos enquanto decorriam as nossas aulas.

A variedade de métodos usados para recolher os dados incluíram: os tickets-out-of-class, as questões sobre as suas visões das nossas disciplinas em relação a outras disciplinas no mesmo curso, narrativas escritas, feedback de um amigo crítico, discussão sobre o que aprenderam numa determinada aula, análise final da sua aprendizagem durante o semestre e as suas visões e experiências de se tornarem professores. Os dados foram recolhidos ao longo do semestre.

\subsubsection{Considerações éticas}

Todos os alunos foram convidados para participarem nos self-studies nas duas disciplinas. Todos anuíram e assinaram o consentimento informado. Os alunos também deram permissão para usarmos citações das suas declarações escritas. As suas questões sobre a investigação foram sempre respondidas de forma pronta e foi reportada uma visão geral dos dados no final das disciplinas. 


\section{Dados- as respostas dos alunos futuros professores}

Nesta secção apresentamos dados que ilustram o modo como os alunos futuros professores olharam para as suas experiências de aprendizagem nas duas disciplinas e como ouvir os seus comentários sobre o nosso ensino conduziram ao reenquadramento dos nossos pressupostos e das mudanças nas nossas práticas. Nesta secção analisamos ainda as descrições dos alunos futuros professores das nossas disciplinas em relação a outras do mesmo curso, o conteúdo e o valor dos tickets-out-of-class e o modo como eles influenciaram a forma como pensamos sobre o nosso ensino. Os dados são apresentados de acordo com os seguintes tópicos:

- Uso dos tickets-out-of-class

- O valor dos tickets-out-of-class

- As visões dos alunos futuros professores sobre as disciplinas em relação a outras no mesmo curso

- Encorajar diferentes formas de pensar sobre o ensino e sobre aprender a ensinar

- Visões dos alunos futuros professores sobre o facto de um formador de professores realizar um self-study das práticas.

\subsection{0 uso dos tickets-out-of-class}

Quer no Canadá, quer em Portugal, os tickets-out-of-class foram usados para obter informação por parte dos alunos no final de cada uma das nossas aulas. Os tickets focaram-se em questões que os alunos futuros professores gostariam de ver respondidas, em comentários sobre as atividades das aulas, em reflexões sobre o processo de aprendizagem dos alunos, em conteúdos e tópicos abordados nas aulas e no questionamento das suas crenças.

Os seguintes comentários de alunos futuros professores portugueses são ilustrativos dos tipos de comentário que um formador de professores pode receber quando pede aos seus alunos para comentarem a sua aprendizagem:

A aula de hoje fez-me pensar sobre quantas teorias e métodos de avaliação existem. Também me fez refletir sobre os instrumentos mais adequados para avaliar a aprendizagem dos alunos.

A aula foi importante e fez-me pensar sobre a utilidade da avaliação. Avaliar é mais do que dar notas. Como professor tenho de estar consciente disso. 
Adorei a aula de hoje, mas estou com receio de fazer um portefólio porque nunca fiz nenhum.

Gostei muito do debate. Fez-me relembrar o que aprendi na aula anterior. Foi divertido tentar convencer o outro grupo de que a avaliação formativa é mais útil no contexto do Ensino Básico. Foi uma forma muito interessante de aprender.

Gostei da interação dos dois grupos. Gosto deste tipo de aulas, ajudam-nos a ser melhores profissionais.

Gostei muito da atividade 2 do portefólio (um incidente crítico sobre avaliação).

Gostei muito desta aula pois ficou claro para mim o que são critérios de avaliação. Estou ansiosa por saber mais sobre o assunto.

Tenho pensado na minha trajetória como aluno. Esta disciplina é interessante, vai influenciar a minha aprendizagem e a minha vida profissional.

Sinto que às vezes a participação ou comentários são um pouco confusos e não totalmente relevantes. Mas acho que os comentários são importantes porque levam à discussão. No final há clarificação.

Sinto-me mais confortável agora nas discussões na aula.

Esta aula foi muito interessante pois comecei a dar sentido à avaliação. Estou ansiosa por aprender mais coisas sobre o assunto. A avaliação é um tópico central para o meu futuro como professora.

Depois desta aula fiquei curiosa sobre o sistema finlandês.

Não sabia que a avaliação era tão complexa. Para mim tinha a ver com testes e notas. Esta disciplina tem sido importante para o meu futuro profissional como professora. Normalmente, no final da aula identifico os aspetos que vou usar nas minhas aulas.

\subsection{0 valor dos tickets-out-of-class na perspetiva dos alunos futuros professores}

Perguntámos especificamente aos alunos futuros professores em Portugal o valor da escrita dos tickets-out-of-class no final de cada aula:

Gosto dos tickets porque me permitem pensar sobre o que aprendi e tornam possível a clarificação de algumas dúvidas que possa ter, pois as questões ou comentários são discutidos na aula seguinte. Também aumentam a interação entre professora e alunos, pois podemos fazer sugestões e comentários sobre a aula. 
São muito importantes já que os alunos podem colocar questões se não se sentirem confortáveis em fazê-las na aula.

Gosto dos tickets porque promovem a interação entre a professora e os alunos. Podemos clarificar dúvidas e é bom ir para a aula seguinte e ver as nossas questões respondidas.

São uma boa forma de clarificar algumas dúvidas e de interagir com o professor. Ajudam a desenvolver uma melhor comunicação e a tornar as aulas mais interessantes.

São úteis porque nos permitem colocar questões para clarificar dúvidas e fazem-nos rever o que aprendemos. Ajudam-nos a relembrar conceitos e podemos fazer comentários ou sugestões sobre o que estamos a fazer nas aulas.

Sim, são úteis porque nos permitem questionar o que aprendemos na aula e, às vezes, discutimos as questões na aula, o que permite rever o que aprendemos.

São úteis no sentido em que clarificam o que aprendemos e até nos permitem fazer uma espécie de sumário no início de cada aula. Os alunos podem não ter as mesmas capacidades para se exprimirem oralmente e os tickets permitem-Ihes expor dúvidas que possam ter sem receio de se exporem.

São muito úteis pois ajudam a clarificar ideias que, às vezes, não estão tão claras. Também promovem a discussão e a partilha de ideias na aula seguinte. São úteis pois os alunos têm voz e permitem que o professor saiba o que os alunos pensam sobre a aula.

São muito úteis pois possibilitam a revisão do que foi aprendido.

\subsection{A visão dos alunos futuros professores sobre a disciplina em relação a outras existentes no mesmo curso}

Os alunos futuros professores do Canadá envolveram-se espontaneamente numa discussão sobre as características peculiares das aulas quando o seu professor esteve ausente uma semana para participar numa investigação no Chile. Todas as sessões da disciplina foram gravadas e, de seguida, apresentamos o que se discutiu na aula em causa a partir da gravação:

Outro perguntou por que é que íamos à aula se o nosso professor não estava lá.

Estamos todos aqui por uma razão, comprometidos em nos tornarmos os melhores professores de Física possível.

Estamos a investir na nossa própria aprendizagem. 
A nossa motivação é intrínseca, não estamos preocupados com as notas ou de sermos criticados.

Este é o único espaço onde podemos colocar questões livremente.

Noutras aulas não podemos exprimir as nossas opiniões de forma livre.

Aqui os conteúdos não são debitados como um Evangelho.

O professor senta-se connosco e ouve o que queremos fazer na aula, ele não se vê como um sábio.

Não é obrigatória a presença na aula, o professor quer que sejamos responsáveis.

Nunca senti que me desprezasse.

O seu entusiasmo por ensinar esta turma é visível.

Os alunos futuros professores em Portugal também escreveram comentários sobre a disciplina em comparação com outras que frequentavam no mesmo curso:

Esta disciplina é muito mais dinâmica do que as outras. Apreendemos muito sobre vários temas mas de uma maneira interessante. A reflexão e a discussão são fundamentais nestas aulas e isto é ótimo para os alunos aprenderem melhor.

Nesta disciplina os alunos podem, por exemplo, fazer sugestões sobre como podem ser avaliados em termos de métodos e de critérios. A relação entre a professora e os alunos é ótima e estamos a praticar constantemente a nossa futura profissão.

Estas aulas são mais dinâmicas e há muita interação entre os alunos e a professora. Ela está sempre a ajudar-nos. Gosto muito do modo como as aulas são conduzidas, não é só transmissão de conhecimento, há momentos divertidos, por exemplo os debates. Aprendemos de diferentes maneiras.

Esta disciplina é mais prática, menos tradicional e baseia-se na discussão e no debate de tópicos. Também gosto muito da parte ética, pois nesta disciplina prevalece a ideia de que "todas as opiniões são tidas em consideração". Gosto disso.

Nesta disciplina a voz dos alunos conta, o que não acontece noutras disciplinas. As aulas são dinâmicas e há muita participação dos alunos. Esta disciplina é dinâmica e fundamental para a minha prática profissional. Escrever um portefólio reflexivo e os debates tornaram a disciplina mais prática e diferente das outras. 
Esta disciplina permite um tipo de trabalho mais prático na aula. Há interação entre a professora e os alunos, as aulas têm um lado teórico e um lado prático. A disponibilidade da professora é fundamental para os alunos aprenderem e o seu feedback é sempre construtivo.

Esta disciplina é diferente das outras porque inclui debates entre os estudantes com o apoio da professora e também por causa dos métodos de avaliação, nomeadamente o portefólio.

\subsection{Encorajar diferentes modos de pensar sobre o ensino e o aprender a ensinar}

Os alunos futuros professores do Canadá, quando questionados sobre o que esperavam fazer de forma diferente nas suas próprias aulas como resultado da frequência desta disciplina, responderam o seguinte:

Esta aula mudou radicalmente a minha filosofia de ensino. Espero implementar uma abordagem de aprendizagem ativa e enfatizar 0 craft knowledge nas minhas aulas e pretendo continuamente aprender e melhorar.

Espero desafiar os alunos a fazer erros e a pensar sobre os conceitos em vez da "resposta certa".

Penso que esta disciplina mudou fundamentalmente o modo como vejo o ensino, muito do que eu faço "de forma diferente" vem diretamente das conversas em que participei nesta disciplina. Especificamente, ter em atenção a Física conceptual é algo que eu quero continuar a fazer quando for para a minha sala de aula.

Espero criar um ambiente semelhante ao que vivi nesta disciplina. Esta disciplina ajudou-me a ver a importância de criar um ambiente de sala de aula onde as pessoas se sentem confortáveis a discutir e a exprimir a sua opinião. Espero também focar-me menos na "matemática" da Física e mais na compreensão conceptual.

Uma resposta simples seria dizer que eu planeio fazer o mesmo. Esta disciplina permitiu-me ter conversas abertas com os meus pares para melhorar as minhas práticas pedagógicas. Na realidade, gostaria de encorajar estas conversas na minha própria sala de aula.

Os alunos futuros professores em Portugal relataram que esta disciplina os encorajou a desenvolver uma forma diferente de pensar sobre o ensino e o aprender a ensinar, como os testemunhos seguintes ilustram: 
Esta disciplina inclui uma variedade de conceitos e de tópicos para nós refletirmos diariamente. Faz-nos pensar sobre vários métodos e sobre o que significa ser professor. É realmente útil a nível pessoal, social e profissional.

Aprendemos vários métodos sobre como avaliar, praticamo-los e discutimos os problemas mais recorrentes no ensino e isso é importante para a nossa vida futura, conseguimos compreender o que pensamos e como ensinar.

Esta disciplina está a dar-me a oportunidade de aprender imenso sobre o ensino e sobre ser professor. Faz-nos aprender como ensinar e aquilo que não devemos fazer como professores, pois há muitos professores que não sabem o que é ser um bom professor.

Esta disciplina torna claro o papel do professor e convida-nos a pensar sobre as nossas práticas profissionais como futuros professores e sobre o modo como os alunos aprendem.

Esta disciplina permite-nos perceber a necessidade de adaptar o ensino e de usar uma variedade de técnicas que aprendemos experimentando na sala de aula.

Trata-se de uma disciplina que permite a discussão de casos reais, de questões fundamentais e é sempre possível debater questões que surgem na sala de aula. Nunca pensei tão seriamente sobre o papel da avaliação e sobre o modo como ela influencia as trajetórias dos alunos. Mudei muito a minha forma de pensar.

Esta disciplina ensina-nos diferentes métodos de ensino experimentandoos na prática e isso permite-nos refletir sobre as experiências de aprendizagem que tivemos como alunos de modo a informar a nossa prática.

\subsection{A visão dos alunos futuros professores sobre um formador de professores realizar um self-study da sua prática}

Os alunos futuros professores do Canadá foram informados no primeiro dia de aulas em setembro que o seu professor pretendia investigar a sua prática de ensino no seu último ano de trabalho antes da reforma. Todos os alunos assinaram um formulário de consentimento para poderem participar. Sete meses mais tarde, em abril, os mesmos alunos foram questionados sobre se se lembravam de como reagiram à ideia e como ela afetou a sua visão da disciplina. Outros formadores de professores podem ser encorajados a realizar um self-study da sua própria prática com base nos comentários que a seguir se apresentam: 
Fiquei muito impressionado com a dedicação à melhoria contínua. Fez-me apreciar a importância de constantemente avaliar a minha prática de ensino com o objetivo de melhorar.

Pensei que era uma ótima ideia! Não há muitos formadores que estejam dispostos a analisar o seu ensino. Fiquei entusiasmado com o desenrolar do ano para ver o que se descobria.

Lembro-me de ter ficado impressionado com a ideia. Muitas pessoas nesta posição terminariam simplesmente o seu último ano tal como fizeram com os anteriores. A ideia de ainda tentar estudar-se a si próprio e experimentar novos conceitos mesmo no último ano de trabalho merece muito respeito.

Pensei que era incrível que mesmo no seu último ano de trabalho, o professor quisesse ainda estudar o seu ensino. Não pensei muito sobre isso nos últimos 8 meses porque não quero que isso influencie as minhas ações nesta disciplina. Mas estou muito interessado em descobrir!

A minha reação foi ter ficado extremamente impressionado. O professor é o único professor que pratica o que defende, respeito-o muito e a esta disciplina desde o primeiro dia.

Foi um misto de confusão e de inspiração! Inspiração porque uma pessoa está motivada e entusiasmada em continuar a estudar a sua prática mesmo até depois da reforma. É uma espécie de estabelecimento do ambiente do que se vai passar durante o ano também, demonstrando a importância de registar as suas atitudes e prática.

A minha reação foi de surpresa que um formador de professores quisesse continuar a estudar o seu ensino. Ajudou-me a olhar para esta disciplina como o início do meu desenvolvimento como professor. A vontade de querer continuar a estudar a sua prática ajudou-me a ver esta disciplina como ponto de partida para desenvolver de forma contínua o meu ensino.

Fez-me sentir que o professor estava, de facto, a investir na formação de futuros professores. Fez-me respeitar de imediato e de apreciar 0 professor e fiquei entusiasmado pelo facto de ir aprender com ele.

Penso que foi o momento em que vi a sua atitude perante a educação e os seus alunos, senti-me agradecido e fez-me assumir mais a responsabilidade em estar neste curso.

Lembro-me de admirar o modo como ele ainda estava a aprender e a refletir sobre a sua prática mesmo no seu último ano de ensino. 
Pensei que era interessante ele falar dos seus estudos. Foi também o modo como ele apresentou o seu estudo. Disse-nos que queria experimentar algo novo. Gostei de ouvir isso e fez-me aderir às atividades que propôs.

Não foi, por acaso. Não será a melhor experiência aquela em que os participantes não estão sabem disso e por isso não há enviesamento? Não tive grande reação quando assinei o consentimento.

\section{0 que aprendemos com 0 self-study das nossas práticas de formação?}

Nesta secção sintetizamos as mudanças que fizemos nas nossas práticas e nas nossas ideias sobre como devemos ensinar os futuros professores. Partilhamos dados suficientes que atestam o valor e a importância de ouvir os nossos alunos e também ilustrámos o possível impacte das mudanças da prática desde o início da investigação self-study na nossa sala de aula.

Iniciámos os nossos self-studies introduzindo a prática de pedir aos alunos futuros professores para escreverem um ticket-out-of-class. Leva tempo até que um formador de professores incorpore e se torne confortável com uma nova prática e o mesmo é válido para os alunos. Preferimos que os tickets sejam escritos de forma anónima; o objetivo é identificar um conjunto de respostas sobre o nosso ensino, não identificar pessoas. As respostas anónimas também permitem que os alunos mais facilmente exprimam insatisfação. É fundamental introduzir novas práticas desde cedo na disciplina, preferencialmente na primeira aula. Uma forma de começar consiste em dar a cada aluno um pequeno pedaço de papel e pedir-Ihes que respondam a uma das seguintes perguntas ou às duas: "Qual foi a ideia mais importante que leva da aula de hoje?" e "Qual foi o tópico que gostaria de entender melhor?". De salientar que o enfoque está no que os alunos futuros professores estão a aprender, aula a aula, evitando a ideia de que o que o formador ensinou foi exatamente o que foi aprendido.

Tivemos várias oportunidades de explorar o modo como os alunos viam as nossas aulas em relação a outras disciplinas do curso. Graças a muitos anos de self-study das nossas próprias práticas na formação de professores, os dados recolhidos tendem a expressar visões positivas em comparação com outras disciplinas. Aqueles que nunca experimentaram o self-study podem perguntar-se se esta comparação é adequada. A formação de professores tende a atrair críticas porque as experiências de estágio são vistas como mais relevantes e obviamente essenciais. Abordar este tipo de comparações pode ser um exercício em si mesmo, porque encoraja os alunos a considerar 
explicitamente a qualidade da sua aprendizagem profissional em cada uma das suas disciplinas. Pode ser facilmente assumido que os alunos futuros professores, agindo individualmente, façam essas comparações e integrem as diferentes disciplinas num todo coerente do ponto de vista do trabalho do professor. Desafiámos este pressuposto nas nossas próprias práticas e descobrimos que os alunos beneficiam consideravelmente da oportunidade de discutir estas comparações na turma, pois haverá distintas opiniões.

Os alunos futuros professores iniciam um curso de formação com muitas crenças sobre o que os professores fazem e por que é que o fazem de determinada maneira. 0 ensino é a única profissão em que os que querem entrar têm milhares de horas de experiência observando o que os professores fazem mas nunca tiveram oportunidade de perguntar o pensam sobre o seu trabalho. Lortie (1975) ficou muito conhecido por caracterizar este background/experiência como a "aprendizagem pela observação". O mesmo autor sintetizou os efeitos negativos desta aprendizagem pouco habitual e não intencional do seguinte modo:

É improvável que muitos alunos aprendam a ver o ensino no quadro de um meio para atingir um fim ou que assumam uma postura analítica sobre ele. Os alunos ficam, sem dúvida, impressionados por certas ações de professores e não por outras, mas não se pode esperar que eles vejam as diferenças do ponto de vista pedagógico ou explicativo. O que os alunos aprendem sobre o ensino, portanto, é intuitivo e imitativo, em vez de explícito ou analítico; baseia-se nas personalidades individuais e não nos princípios pedagógicos (p. 62).

Os nossos self-studies levaram-nos a abandonar o pressuposto de que há uma forma certa de ensinar que todos os alunos futuros professores devem aprender. Agora assumimos que o conhecimento anterior que é extenso (mas muito incompleto), adquirido pela experiência, não pode ser substituído pela transmissão da ideia de que eles devem ensinar de uma determinada maneira, mesmo que esteja apoiada por uma investigação ampla. Os alunos futuros professores aprendem com muitos e diferentes formadores e aprendem não só o que eles ensinam mas também COMO ensinam. As discussões sobre a nossa própria aula em relação a outras no curso proporciona oportunidades importantes para se ser "explícito e analítico" sobre os princípios da pedagogia.

No ano de 2018-2019, Russell conduziu um self-study do seu ensino, que teve a duração de 8 meses, na disciplina de métodos de ensino de Física no ano anterior à sua reforma. No primeiro dia em que conheceu os alunos, explicou que iria fazer um self-studye convidou-os a assinar o consentimento informado na qualidade de participantes no sentido de partilharem os seus dados à medida que o curso avançava. O self-study tinha sido objeto de aprovação ética pelo General Research Ethics Board da universidade. No 
final de três semanas, perguntou aos alunos como reagiram ao facto de 0 seu professor estar a estudar o seu ensino. 0 pressuposto de Russell era que eles tinham facilmente esquecido o aspeto do self-study da sua prática na sala de aula. Como os dados acima descritos revelaram, quase todos ficaram impressionados em relação ao facto de o seu professor estar a modelar o que eles esperavam das experiências de estágio e dos primeiros anos de ensino. É, pois, importante considerar, de forma cuidada, os nossos pressupostos sobre como os alunos responderão a movimentos pedagógicos específicos. Numa perspetiva metacognitiva, é também importante partilhar com os nossos alunos as nossas racionalidades sobre novas abordagens pedagógicas que introduzimos. Na nossa visão, os self-studies, como os que descrevemos neste artigo, oferecem possibilidades valiosas para "criar oportunidades para ampliar a compreensão do ensino como algo meramente técnico e incluir perspetivas e experiências sobre a natureza dinâmica, problemática, complexa e sofisticada da prática" (Loughran \& Menter, 2019, p. 222).

\section{Conclusões}

Os conceitos de voz pedagógica e aprendizagem produtiva têm implicações importantes para os formadores de professores que estão interessados em analisar as suas práticas para melhorar a formação de professores a partir de dentro. Ouvir as experiências dos alunos futuros professores de diferentes modos nas nossas aulas deu-Ihes um sentido de voz na sala de aula ao mesmo tempo que nos proporcionou perspetivas únicas sobre a qualidade da sua aprendizagem profissional. Ambos usámos os tickets-out-of-class de forma bem-sucedida e ambos respondemos aos comentários dos nossos alunos ao atender às suas preocupações de forma explícita e ao adaptar o nosso ensino quando as suas sugestões eram consistentes com os nossos objetivos e princípios.

A pedagogia da formação de professores constitui uma preocupação central para quem está envolvido no processo de aprender a ensinar: como se ensina faz a diferença, pois os alunos estão sempre a pensar sobre como é que eles próprios vão ensinar. Ambos acreditamos firmemente na importância de tornar a nossa pedagogia de formação de professores transparente, explicitando a racionalidade da nossa prática e explicando como e por que é que estamos a fazer mudanças em resposta aos seus comentários anónimos. Neste sentido, temos a oportunidade de familiarizar os alunos futuros professores com a aprendizagem double-loop, partilhando com eles os nossos esforços para identificar os nossos pressupostos e as formas como eles evoluíram, pois o self-study permite-nos aprender a partir da nossa experiência como formadores de professores. Pensamos que é importante clarificar os 
vários comentários e questões e convidar outros elementos da aula a indicar, durante a discussão, se concordam ou não. Estas discussões tipicamente criam confiança entre os elementos de uma turma.

Como formadores de professores, começámos a investigar a nossa própria prática de forma cauta, com dúvidas e incertezas sobre onde a investigação nos levaria. Estamos agora entusiasmados com o valor do self-study nas práticas da formação de professores quer para nós próprios, quer para os nossos alunos. Esperamos que este artigo possa encorajar outros formadores de professores a assumir riscos semelhantes de forma a explorar a aprendizagem double-loop, a identificar os pressupostos sobre como as pessoas aprendem a ensinar e depois desenvolver novas práticas de ensino que são verificadas pela escuta atenta das respostas dos alunos.

\section{Referências bibliográficas}

Argyris, C. (1991, maio-junho). Teaching smart people how to learn. Harvard Business Review, 69(3), 99-109.

Bouckaert, M. \& Kools, Q. (2018). Teacher educators as curriculum developers: Exploration of a professional role. European Journal of Teacher Education, 41(1), 32-49.

Costa, A. L. \& Kallick, B. (1993). Through the lens of a critical friend. Educational Leadership, 51(2), 49-51.

Czerniawski, G., MacPhail, A. \& Guberman, A. (2017). The professional development needs of higher education-based teacher educators: An international comparative needs analysis. European Journal of Teacher Education 4O(1), 127-140.

Comissão Europeia (2013). Supporting teacher educators for better learning outcomes. Brussels: Retrieved from https://bit.ly/2qXukD5

Flores, M. A. (2001). Person and context in becoming a new teacher. Journal of Education for Teaching, 27(2), 135-148.

Flores, M. A. (2014). Developing teacher identity in pre-service education: experiences and practices from Portugal. In L. Orland-Barak and C. J. Craig (Eds.), International teacher education: Promising pedagogies (Part A) (pp. 353-379). Bingley, UK: Emerald.

Goubeaud, K. \& Yan, W. (2004). Teacher educators' teaching methods, assessments, and grading: A comparison of higher education faculty's instructional practices. The Teacher Educator, 40(1), 1-16.

Izadinia, M. (2014). “Teacher educators' identity: a review of literature. European Journal of Teacher Education, 37(4), 426-441.

Kitchen, J. (2005) Looking backwards, moving forward: Understanding my narrative as a teacher educator, Studying Teacher Education, 1(1), 17-30. 
LaBoskey, V. K. (2004). The methodology of self-study and its theoretical underpinnings (pp. 817-869). In J. J. Loughran, M. L. Hamilton, V. K. LaBoskey, and T. Russell (Eds.) International handbook of self-study of teacher education practices. Dordrecht, The Netherlands: Kluwer.

Livingston, K. (2014). Teacher educators: Hidden professionals? European Journal of Education 49(2), 218-232.

Lortie, D. C. (1975). Schoolteacher: A sociological study. Chicago, IL: University of Chicago Press.

Loughran, J. (2005). Researching teaching about teaching: Self-Study of teacher education practices. Studying Teacher Education, 1(1), 5-16.

Loughran, J. (2009). A construção do conhecimento e o aprender a ensinar sobre o ensino. In M. A. Flores and A. M. Veiga Simão (Org.). Aprendizagem e Desenvolvimento Profissional de Professores: Contextos e Perspectivas (pp. 17-37). Mangualde: Edições Pedago.

Loughran, J. J., Hamilton, M. L., LaBoskey, V. K. \& Russell, T. (Eds.) (2004). International handbook of self-study of teaching and teachereducation practices. Dordrecht: Kluwer.

Loughran, J. \& Menter, I. (2019) The essence of being a teacher educator and why it matters, Asia-Pacific Journal of Teacher Education, 47(3), 216-229.

Meeus, W., Cools, W. \& Placklé, I. (2018). Teacher educators developing professional roles: frictions between current and optimal practices. European Journal of Teacher Education 41(1), 15-31.

Moreira, M.A. \& Vieira, F. (2012). Preservice teacher education in Portugal. The transformative power of local reform. In J. M. Paraskeva and J. Torres (Eds.), Globalism and Power: Iberian Education and Curriculum Policies (pp. 94-105). New York: Peter Lang.

Murray, J., Swennen, A. \& Shagrir, L. (2009). Understanding teacher educators' work and identities, in A. Swennen, and M. van der Klink (Eds.), Becoming a Teacher Educator: Theory and Practice for Teacher Educators (pp. 29-44). Dordrecht: Springer.

Ping, C., Schellings, G. \& Beijaard, D. (2018). Teacher educators' professional learning: A literature review. Teaching and Teacher Education, 75, 93- 104.

Russell, T. (2005). Can reflective practice be taught? Reflective Practice, 6(2), 199-204.

Russell, T. (2014). One teacher educator's career-long development of a pedagogy of reflection. In L. Orland-Barak and C. J. Craig (Eds.), International teacher education: Promising pedagogies (Part A) (pp. 55-72). Bingley, UK: Emerald.

Russell, T., Fuentealba, R. \& Hirmas, C. (Eds.) (2016). Formadores de formadores, descubriendo la propia voz a través de self-study. Santiago, Chile: Organización de Estados Iberoamericanos. Retrieved from https://bit.ly/36IWhxJ

Russell, T. \& Loughran, J. (2005). Self-study as a context for productive learning. Studying Teacher Education, 1(2), 103-106.

Russell, T. \& Martin, A. (2014). A importância da voz pedagógica e da aprendizagem produtiva nos programas de formação inicial de professores, in M. A. Flores (Ed.) Formação e desenvolvimento profissional de professores: contributos internacionais (pp.1740), Coimbra: Almedina.

Schulte, A. (2005). Assuming my transformation: Transforming my assumptions. Studying Teacher Education, 1(1), 31-42.

White, S. (2019). Teacher educators for new times? Redefining an important occupational group. Journal of Education for Teaching, 45(2), 200-213. 